\title{
GLORIA FUERTES. EMPATÍA Y RADICALIDAD PACIFISTA
}

Josemi Lorenzo Arribas

Universidad Complutense de Madrid josemi20@ hotmail.com

Recibido: 22-02-2011

Aceptado: 31-03-2011

\section{Resumen}

Gloria Fuertes fue una mujer inapropiable. A su éxito televisivo como "poeta de los niños" se contrapone su desconocimiento como "poeta de adultos" y su falta de reivindicación por ideologías o movimientos que naturalmente debieran haberlo hecho (feminismo, antimilitarismo, lesbianismo...). Una de las constantes que animan su obra es su pacifismo radical, innegociable, y su obra constituye uno de los ejemplos más extensos de compromiso con la consecución de la paz y la denuncia de la violencia y quienes la promueven. Su empatía con las personas que sufren y su punto de vista situado la sitúan en una posición que hemos denominado de "beguina laica", aportando un enfoque original sobre la obra de esta gran poeta madrileña del siglo XX.

Palabras clave: Feminismo, antimilitarismo, literatura, poesía.

\begin{abstract}
Gloria Fuertes was an inappropriable woman. Her TV success as "poet of children" is opposed by her ignorance as "poet of adults" and her lack of claim for ideologies or movements that naturally should have been done (feminism, antimilitarism, lesbianism...). One of the constants that cheer her work up is her radical pacifism, not negotiable, and her work constitutes one of the most extensive examples of compromise to the achievement of the peace and denunciation of the violence and those who promote it. Her empathy with those who suffer and her point of view placed place her in a position which we call "secular beguine", what contributes to an original approach about the work of this great Madrid poet of the twentieth Century.
\end{abstract}

Key words: Feminism, antimilitarism, literature, poetry. 
A Toni Álvarez, insubmís i mestre

El pacifismo se nos ha quedado antiguo.

Ahora somos antimilitaristas.

(Gloria Fuertes)

\section{Introducción}

Parece que escribir sobre pacifismo radical, o antimilitarismo, es empeño que no cabe dentro de lo que la tradición académica admita como propio. Da la impresión, al observar el rechazo que suelen generar, que dicha óptica se identifica como amenazante, descalificada por el sencillo procedimiento de la falta de rigor o, casi peor, tachada de "militante". Curioso procedimiento el de la escritura científica, que tantas veces trata, estudia, disecciona (y abusa de) textos precisamente militantes, a ser posible cuando han pasado a formar parte de cierto canon y, por tanto, desactivados de su inicial potencia crítica.

Como fue inevitable en mi generación, leí a Gloria Fuertes (1917-1998) primero de niño, siendo ávido lector de su poesía infantil, animado por mi madre y por mi padre. Como ha sido infrecuente en mi generación, luego, de mayor, disfruté de su poesía no infantil, pero con ruptura entre una y otra etapa y necesario redescubrimiento o, mejor, descubrimiento a secas, pues apareció ante mis ojos una escritora distinta, que nada tenía que ver con la que había leído de pequeño. Antes bien, en mi experiencia, la primera perjudicó a la segunda, habiendo de vencer un prejuicio extendido en la sociedad que me tocó vivir en torno a la figura de Gloria.

En ocasiones, el proceso de investigación produce una identificación tal, un amor hacia el personaje, que, al margen de que sea sano desde un punto de vista académico o no, da la sensación, durante un tiempo, de que dicha investigación ilumina un horizonte, y todo lo ocupa dicho personaje. Obvia decir que a uno, más acostumbrado a investigar mujeres de hace muchos siglos, le ha pasado esto con Gloria Fuertes y, en la medida de lo posible, he intentado, en los últimos años, que en territorios académicos liminares tuviera presencia su obra (he cambiado esto un poco), siquiera humildemente. El resultado ha sido siempre el mismo, alentador. Sorpresa por parte de quienes tenían oportunidad de redescubrirla, y mucho interés ante la "nueva" Gloria que aparecía ante ojos y oídos, con categoría de revelación. 
Para alguien que, como yo, no soy filólogo ni estoy especializado en literatura contemporánea, sino que mi acercamiento a ella es como simple usuario y beneficiario de poetas y poesías, descubrí que muchos de los hilos que el análisis de los poemas de Gloria me sugerían estaban escritos ya por los no muchos críticos que se han dedicado a estudiar su obra. También comprobé, sorprendido, el escasísimo número de historiadoras de la literatura y filólogas que lo han hecho, apenas ninguna española. Esta mirada externa, finalmente, me ha servido para advertir que hay muchas ganas de contar cosas en artículos que presuntamente tratan sobre un tema específico, pero se detienen en largas y jugosas introducciones para contextualizar una obra que, por sus características formales, es necesario situar. Hay mucha pasión en quienes estudian a esta poeta, pasión "buena", de la que no empaña el juicio crítico. El peso que ha tenido la crítica norteamericana a la hora de analizar a la autora también explica esta necesidad, todavía mayor, de contexto y tejido en el que poner a Gloria.

Así, se ha insistido, a la hora de analizar su poesía, en aspectos puramente filológicos, como los juegos de palabras (García Page, 1990 y 2003; Benson 2003), los manejos lingüísticos (Debicki, 1986; Folkart, 2000/2001), el tono coloquial y popular de su lenguaje (Mandlove, 1987-1988; Fernández Rodríguez, 1998 y 1999), el uso de la primera persona y el sentido autobiográfico de su escritura (Sherno, 1989-1990; Morris, 1991; Pellarolo, 1992; Acereda, 1999), el humor como herramienta fundamental de producción de significados (Persin, 1988), la parodia (Browne, 2000; Ten Hacken, 2007), la ékfrasis (Reina Ruiz, 2003). También en los aspectos contextuales más conflictivos, entrando en cuestión de puros contenidos, analizando la carga crítica de su obra (Acereda, 2000), su homosexualidad (Sherno 1989/1990; Acereda, 2002), la centralidad del hambre (Capuccio, 1993), la originalidad de su producción (Benson, 2000), la relación con la poesía de otros poetas (Mandlove, 1983; Benson, 1994) y otras poetas (Payeras Grau, 2003; García Selma, 2004), o su particular experiencia de su condición femenina (Ramón, 2006). Falta un apartado importante, bajo mi punto de vista, que daría de sí, y es el tratamiento siempre indulgente, empático y desprejuiciado de la prostitución. Las mujeres (y los travestis) dedicadas a este oficio ocuparon una parte muy significativa en la obra de Gloria, y no fueron tiempos buenos en el tratamiento literario de este colectivo, secularmente marginalizado. Y por supuesto, el lugar que ocupa el deseo de paz y su continuo rechazo de la guerra, un aspecto que atraviesa la obra de la autora, apenas percibido por quienes se han ocupado de ella (tan sólo una genéricas referencias: Acereda, 1999: 161; Ten Hacken, 2007: 119, nota 44). 


\section{Una mujer inapropiable}

No se trata ahora de intentar atraer a Gloria a una u otra fratría militante (feminismo, antimilitarismo, lesbianismo...), sino de reconocer su naturaleza inapropiable que contrasta paradójicamente con ese lenguaje sencillo que a todo el mundo llega y todo el mundo entiende, guste o no. Se puede decir que Gloria Fuertes, en el contexto de la investigación académica, es un ejemplo de antiheroína. Muy incómoda también para los distintos grupos ideológicos. No ha sido reivindicada por nadie, salvo por un sector sorprendentemente pertinaz del hispanismo estadounidense, como se decía, que no ha dejado de escribir sobre ella. Una pausada reflexión sobre este hecho permite localizar los porqués de su incomodidad, y llegamos a entender que ni la derecha ni la izquierda parlamentaria (Acereda, 2002) hayan reivindicado a Gloria (no creo que el rechazo proviniera de su puesto como simple secretaria del Ministerio de Información y Turismo durante la Dictadura. Mayores cargos, por ejemplo, ostentaron miembros de los gobiernos del PSOE en anteriores administraciones franquistas), que haya sido una mujer despreciada en el ambiente académico, en los cenáculos poéticos y que, paradójicamente, sea una ídola popular gracias a su poesía infantil.

Apuntamos en esta breve introducción un factor que ha podido coadyuvar a su deliberado olvido: su pacifismo radical, actitud que seguramente contribuyó también a su indigeribilidad, y no sólo el lesbianismo, opción que desde luego tampoco ayudó. De hecho, el antimilitarismo, hoy por hoy, muestra su fractura con el orden dominante en términos de "no asimilación", y se ha mostrado difícil de fagocitar, de resignificar y resemantizar (peor suerte ha corrido el ecologismo y otras tendencias que, aunque arteramente, tratan de ser apropiadas por intereses alejados de sus planteamientos radicales). En esa estela, aun sin ninguna etiqueta ni adscripción, sino por intuición y modo de ser, se sitúa Gloria. El amor, tantas veces señalado como leit-motiv y motor vital en la vida y obra de la poeta, trasladado a su vertiente más social también apunta a ese pacifismo radical, aunque no fuera avant la lettre ni feminista, ni cristiana, ni antimilitarista. Seguramente fue todo eso sin necesidad de grandes teorizaciones, vinculando la experiencia como principal legitimación. En el caso que nos ocupa, un ejemplo de ansia por la paz, de otro modo de mirar y de enjuiciar el mundo, haciendo de este tema un continuum que llegará hasta sus últimos días, y que expresó lapidariamente:

La paz no es mi fin sino el medio de conseguir ese fin. 
(“La paz no es mi fin". OI, 338) ${ }^{1}$

Hace poco, con motivo de una exposición sobre la editorial El Ruedo Ibérico, leía en el pequeño catálogo de la misma unas interesantes palabras vindicativas de Alfonso Rodríguez Castelao. Se recordaba cómo en 1966 esta editorial publicó El pensamiento político de Castelao, contraponiendo una nueva lectura crítica a la versión “folclórica" que de él hacía el Régimen en su celebración de XXV Años de Paz. Este libro ofreció la otra cara, la quizá verdadera, de un autor al que se trató de desactivar ideológicamente (Berzal de la Rosa, 2010: 46). En este caso, llevando la analogía a la poeta, el Régimen lo fue tanto el tardofranquismo como la democracia, en sus etapas distintas, y hasta hoy, pues ninguno le ha tratado bien. Se reconoce a una Gloria "poeta de los niños", enhebradora de fáciles rimas consonantes y soluciones infantiles, mientras una silente y casi unánime voz se niega a mirar hacia el otro lado de su obra, hacia otros puntos de fuga de su único corazón. No hay dos Glorias, ni una autora esquizofrénica.

Mujer, soltera, sin hijos, gorda, lesbiana (todavía parece que no puede hablarse con libertad de este tema), fumadora, bebedora, masculina en modos, en vestir, en aficiones y poeta... y triunfante. Gloria, la poeta de los niños, la de los triunfos televisivos y el reconocimiento mediático, tiene uno de los poemarios más tristes y dolorosos del siglo XX. La poeta de los ripios, los pareados, los divertidos juegos de palabras, tiene una poesía profunda y certera, emboscada detrás de tales recursos. Una deliberada dejación de la forma, huyendo siempre de las complejidades retóricas, en pos de un peliagudo contenido, molesto.

\section{Mística y empatía a través del dolor. ¿Una beguina laica? o el pacifismo como consecuencia necesaria}

Es cierto que escribir sobre la poesía de Gloria Fuertes tiene algunos problemas añadidos, como el carácter oral de su escritura poética, que se formaliza en una voz continuamente plasmada en primera persona del singular, que concede un claro valor autobiográfico a gran parte de sus poemas. De paisaje de fondo, una y otra vez, la Guerra Civil que le tocó vivir, y la imprecación a un Dios distante, aunque siempre presente:

\footnotetext{
${ }^{1}$ Agradezco a la Fundación Gloria Fuertes y a su Presidenta, Luzmaría Jiménez Faro, el permiso para reproducir los poemas que acompañan este texto.
} 


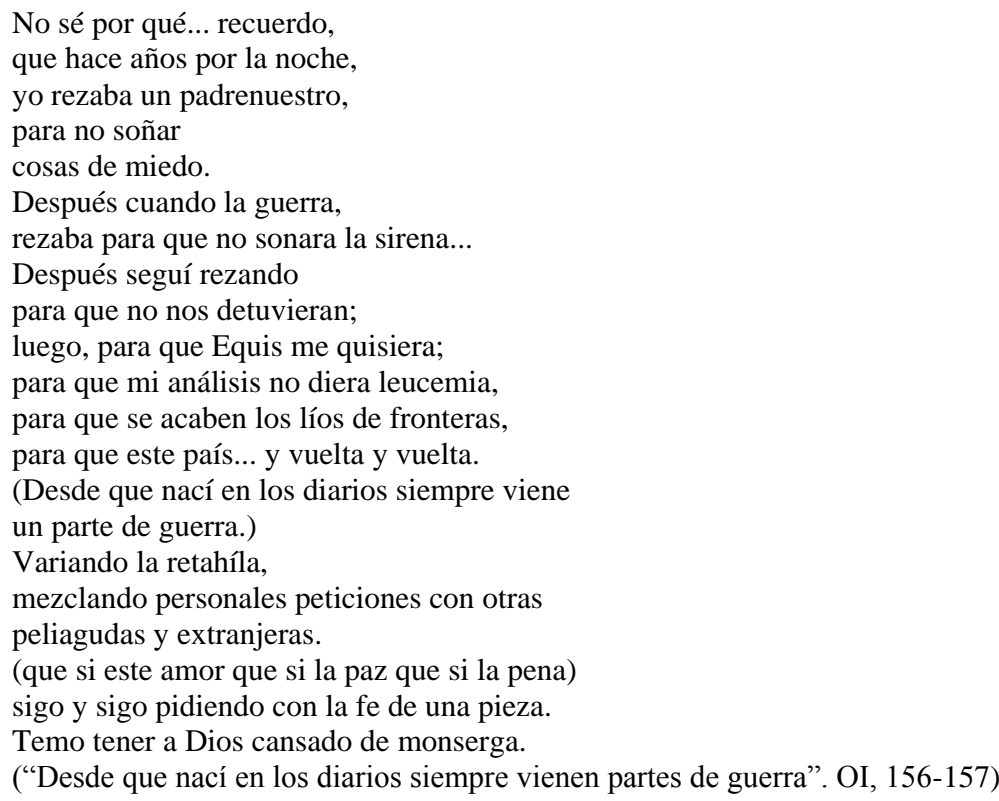

Este registro, aparentemente personal, casi íntimo y opuesto (también sólo en apariencia) a la adscripción política, le ha valido también su invisibilidad desde los movimientos que naturalmente pareciere que debieran haberla reivindicado, como si filiación y afiliación fueran lo mismo. Gloria fue apartidaría políticamente ("Mi partido es la paz”. MVP, 173), opción que, claro está, no implica inanidad política fuera de los esquemas convencionales, como bien han enseñado movimientos emancipatorios de las últimas cuatro décadas.

En este mundo de siglos.

En este mundo de siglas,

De ideas y de partidos

(todos partidos en dos),

desde siempre yo me afilio

yo pertenezco al AMOR.

Desde siempre y no lo oculto

-a otros líderes no insulto-

mas no respeto más leyes,

que las del A., Eme., O. y Erre.

La de amar y ser amado

y lucho sin ser soldado, sin armas y con decoro, porque yo soy de esa raza que por amor dejo todo. ("Mundo de siglas". MVP, 146) 
Fruto de esa no adscripción parece que viene el no reconocimiento por parte de movimientos que necesariamente son afines a su modo de ser, estar y parecer, como el feminismo, el propio antimilitarismo (no fue militante ni en uno ni en otro), y por supuesto la crítica literaria, porque no se asimiló a ninguna escuela, capilla, fratría o conventículo al uso, de esos que van escribiendo la historia con categorías cómodas. En este sentido, quizá no sea una metáfora demasiado descabellada el pensar a Gloria como una suerte de beguina laica en pleno siglo XX. Renunció abiertamente a participar de las características básicas de la poesía como una religión, donde el vate ocupa un estatus sacerdotal, de mediación entre lo trascendente y el resto de la humanidad, y construyó un mundo personal donde tuvieron acceso las personas que ella quiso que estuvieran cerca, entre ellas, la gente del barrio y los colectivos más humildes de entre ésta. Obviamente, quienes no construyen canon literario ninguno.

Siempre estoy con los sitiados nunca con los sitiadores.

(“[Siempre estoy con los sitiados]". ED, 29)

Al igual que los movimientos de mujeres de religiosidad no reglada que comienzan a proliferar en la Plena Edad Media en Europa (beguinas, begardas, emparedadas...) y llegan a la península Ibérica a finales de la misma bajo la figura de la beata, Gloria adquiere un estatus que le granjea la libertad de ser y de decir, de poder escribir lo que quiere y como le da la gana, rompiendo con aquello que tradicionalmente se le exige a un poeta. Ni siquiera es una "poeta social", y tan sólo al postismo se la ha podido vincular por orígenes y amistades. Se sitúa en un "más allá" del orden simbólico patriarcal, lejos de una actitud abiertamente enfrentada, o "contra". Las beguinas renunciaron tanto al matrimonio como a la vida reglar, monástica, situándose fuera del esquema que el patriarcado ofrecía a las mujeres de su tiempo. Decidieron llevar un modo de vida siguiendo "principios apostólicos" pero sin realizar votos, careciendo de regla y sin establecer dependencias orgánicas con respecto al poder (masculino). Paradójicamente, esta debilidad fue su fortaleza. La de la libertad de ser y el libre decir y hacer. Algunas de ellas harán de la escritura, otra práctica no prevista para las mujeres, un medio de expresar su libertad, y en el entremujeres desarrollaran unas prácticas lectoescritoras que me hacen recordar a la Gloria que funda "Versos con faldas", grupo femenino compuesto por ella y sus amigas Adelaida Lasantas, María Dolores de Pueblos y Acacia Uceta con las que recorrió bares y cafés de Madrid recitando versos. Era 1951. 
Alguna estudiosa de su obra ha llegado a hablar incluso del "cuarto propio" que Gloria se construyó, en relación con la habitación para sí que reclamó Virginia Wolf (Sherno, 1990). Igual que las beguinas construyeron y habitaron los suyos, al margen de los espacios codificados tradicionalmente para tales comunidades (el monasterio). Al igual que éstas, además, Gloria no vivió en matrimonio, sino sola y, lo peor, en soledad (una de las sensaciones que le acompañó toda su vida. [Estoy soltera]. ED, 11-12). Y la no dependencia de ningún varón (la mal llamada soltería, pues ¿por qué linguística y socialmente el referente estable de contrastación ha de ser el estado matrimonial?) en la España de las décadas centrales del siglo XX era una anomalía, no siendo monja.

El resultado de la actividad de las beguinas se tradujo en una gran aceptación popular (no olvidemos su vida netamente urbana) y la paralela sospecha por parte de las autoridades, recelosas de un movimiento original que se negaba a ser controlado, y que además no entraba en abierta confrontación, limitándose a soslayar partes fundamentales del sistema. La opción vital de Gloria podría ser entendida como la de una beguina laica en este sentido (sería difícil hablar de "laicismo" en la Edad Media), como alguien que habla desde sí, que hace de su cuerpo, de su atuendo, de su uso, de su voz, de su deseo, un vehículo de comunicación de un mensaje al margen de los discursos oficiales, poéticos o no. Beguina porque no renuncia al mundo ni se retira de él, sino que, incardinándose, media por quienes no tienen voz, dándoles la suya, encarnándose en esas gentes.

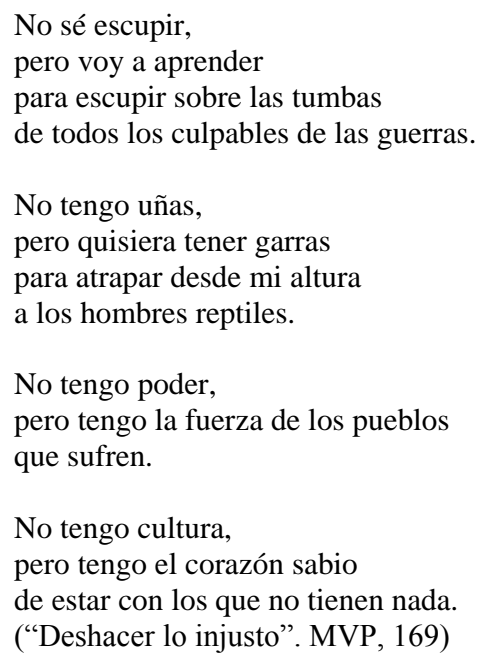


Una beguina que, con ansia de trascendencia a través del registro lírico, cambia el beaterio por la bodega, el parnaso por el barrio, la comunión diaria por la botella de vino blanco, diaria también, en la taberna Antonio Sánchez de su barrio natal de Lavapiés, y troca el hábito, por mucho que no haga al monje, por otro hábito, el de fumar, haciéndose una con el cigarro, perpetuamente encendido. Como los albañiles de los andamios. Como las putas de la plaza de Tirso de Molina.

Su obra y su vida, al margen de los caprichos de la fortuna, al margen de su éxito televisivo y el consiguiente en ventas de libros infantiles, continúa por los derroteros por los que siempre transitó. No se dejó nunca de identificar con las víctimas, víctimas en general, de lo que fueran, con las/os perdedoras/es. En su escritura se trasluce una empatía total con las/os sufrientes, sean quienes sean y un rechazo a los poderosos, sean quienes sean también.

Fruto de esa interiorización del sufrimiento ajeno, surge un pensamiento que rompe con la lógica binaria, esa que se instaló como principio identitario de un modo de pensar el mundo propio de Occidente, que es decir propia de las maneras androcéntricas de regular la vida.

Hablando bien y tarde,

tarde porque no llegué a separaros

ni a los republicanos de los fascistas

ni a los americanos de los camboyanos

ni a los americanos de los vietnamitas.

No llegué a separaros.

$\mathrm{Ni}$ a los surafricanos de los blancos

ni a los negros de los otros negros

ni a los servios de los croatas

ni a los alemanes de los judíos.

No llegué a separaros.

$\mathrm{Ni}$ a los judíos de los árabes

ni a los árabes de los croatas.

hablando bien y tarde

Casi todos sois unos malvados cabrones sin corazón

(hablando mal y pronto.)

("Hablando bien y tarde. Hablando mal y pronto". MVP, 162)

No hay tregua para los culpables en la obra poética de Gloria Fuertes. Incansable, hila reflexiones trascendentes y anécdotas concretas, cambia de registro para hacer 
entendible un único mensaje, y escupe maldiciones contra quienes destruyen la vida. Son las verdades del barquero puestas en el verso buscadamente imperfecto de la poeta.

Era la era de la guerra,

frío, enfermedad,

muerte y hambre.

Las campanas que invitaban a la oración

eran utilizadas para munición de destrucción.

(Alto grado de deterioro del corazón del hombre).

La embarazada se refugió en la puerta,

la granada chocó contra el quicio,

por el aire saltó el niño.

Los niños mueren de hambre o de metralla,

al que disparó el cañón le dan una medalla.

("Era la era de la guerra". MVP, 162-163)

Este proceso empático se presenta, antes que como el resultado de un proceso intelectualizado, como una actitud intuitiva, necesaria, que, en su caso, le llevará a escribir como habla el pueblo y llegará a ser uno de los rasgos de estilo más significativos. Si para la sociedad biempensante las palabrotas están mal vistas, cuánto más en una mujer:

El taco.

Nada de que es pobreza de lenguaje

es todo lo contrario

riqueza y libertad de nuestro idioma.

¡Coño con los señores académicos que no sueltan uno!

(así les va en la vida).

El taco evita bofetadas

bronquitis y altercados,

es ético, gracioso y sano

«canto por no llorar».

Yo taqueo por no matar.

(“En defensa del taco". ED, 64)

Ella fue perdedora, como tantas/os conciudadanas/os, por el hambre que pasó durante la guerra; después, fue perdedora por ideología; vitalmente, por el rechazo a sus características físicas o sus opciones sexuales; desde que nació, por su condición sexuada en femenino en un mundo patriarcal. Quizá por ello, esa empatía hacia los pobres, los desheredados, a los que regala versos con una infinita solidaridad hacia ellos, y hacia ellas. La guerra, o su amenaza, late como terrible paisaje de fondo (una y otra vez el recuerdo de la Guerra Civil), así como la rabia hacia quienes la sostienen. Lo hemos visto en poemas anteriores, y serían decenas los que se podrían citar: 
Las flacas mujeres de los metalúrgicos

siguen pariendo en casa o en el tranvía.

Los niños van algunos a las Escuelas Municipales,

y se aprenden los ríos porque es cosa que gusta.

Las niñas van a las monjas que enseñan sus labores y a rezar.

De la ciudad se va borrando poco a poco la huella

de los morteros.

¡Han pasado tantos meses!

He visto en sueños, que hay varios señores

hablando en una mesa de divisas,

de barcos, de aviones, de cornisas

que se van a caer cuando las bombas.

y yo pido perdón al Gran Quien Sea,

por desearles una buena caja,

con cuatro cirios de los más curiosos.

("Las flacas mujeres". PS, 57)

Y, por encima de todo, una palabra que aparece frecuentemente en sus textos y en la que nos debíamos parar a reflexionar: misericordia. Ésta define la actitud de Gloria Fuertes hacia el ser humano. Desde ahí estableció su compromiso con la sociedad que le tocó vivir. Compromiso brutal y sin fisuras. Claro que, frente a la imagen edulcorada de la poeta que proyectaba la tele en blanco y negro de los años setenta no había quien contrapusiera la de la poeta de los versos tremendos. Ésos no importaban, ni siquiera para hacer carnaza mediática ante algún poema que aparentemente debiera excluir a Gloria de los horarios infantiles. Desconozco si se le preguntó alguna vez (no he leído nada al respecto ni nada encontré) por uno de los poemas que más me impresionaron de los insertos en Mujer de verso en pecho (1995). No tiene título, y dice así:

\footnotetext{
Si sólo pudiera votar contra una ley no votaría contra la ley del aborto.

Un feto de dieciocho días

vale menos que un hombre de dieciocho años

- edad en la que «caen» todos

en ese «aborto colectivo» para adolescentes

que suelen organizar

los que siempre votan contra el aborto-.

(MVP, 173)
}

Basta recordar los debates habidos en España sobre tema tan sensible como éste para admirar a quien, habiéndose granjeado su bienestar con su labor con niñas y niños, se atreve a mostrar por escrito su opinión, abiertamente encontrada con la de 
tantas madres y padres que compraban los libros de versos infantiles para aficionar a la prole a la lectura. Valentísima manifestación, que no apunta a un sí o a un no, como quieren los políticos cuando de discutir una ley se trata (así estaba polarizado el debate en el Parlamento y en sus extensiones mediáticas), sino que va mucho más allá, aleja el punto de fuga, y ensancha el horizonte permitiendo pensar el problema de otra manera. Uno de los más bellos e indirectos poemas antibélicos (antimilitaristas, si se definiera desde los principios de este movimiento) de la trayectoria de la poeta.

\section{Reivindicación de las mujeres}

La poesía de Gloria Fuertes, siempre y en última instancia, está destinada a la oralidad, una forma de decir que se puede relacionar con lo históricamente considerado como característico de la "escritura de mujeres". La consciencia de este hecho agudiza los juegos con el lenguaje a partir de la mera sonoridad de las palabras, explotando sus posibilidades fonéticas, y de ahí la amplia gama de recursos retóricos que se despliegan en relación con este asunto: aliteraciones, paronomasias, asíndetos, quiasmos, anáforas... Las mujeres, en cuanto grupo marginado por el régimen socio-simbólico patriarcal, también fueron objeto de la mirada gloriana. No las mujeres en su conjunto, sino algunos conjuntos de mujeres (las pobres, las prostitutas, las malcasadas...). Pero también hay impugnaciones sutiles, burdas en apariencia y tremendamente eficaces, que ponen en entredicho el sistema dominante.

Un aspecto poco estudiado, pero muy interesante por ser una marca de autora, es el cambio de género gramatical de algunos términos con respecto a su uso corriente, hecho que se puede poner en relación con su resistencia al empleo de algunas palabras de doble terminación para evitar lo que en un uso no sexista de la lengua se conoce como duales aparentes, es decir, la asimetría semántica de dos vocablos con el mismo lexema, según se genericen en masculino o en femenino. El ejemplo más claro lo ofrece la propia definición con que Gloria se describía a sí misma: poeta, con rechazo explícito a la forma poetisa. Con los conceptos, o conceptualizaciones, sencillamente les da la vuelta, con procedimientos cuanto más chuscos y sencillos mejor (como en su obra de teatro Las tres reinas magas). Este uso antinormativo de algunas palabras es una forma eficaz de resistencia a una lógica del lenguaje que se presenta como natural, cuando no es sino convención. Por este sencillísimo procedimiento, que no hace falta explicar y que 
todo el mundo entiende, se marcan también horizontes simbólicos, poéticos y políticos. El lenguaje describe, pero también crea, da existencia y, sobre todo, dota de sentido.

Por procedimiento inverso, inventó nuevas palabras por el sencillo recurso de doblarles la terminación con el género gramatical opuesto al que su uso prescribe. La libertad por la que Gloria luchó en vida se dobló, sin duda ninguna, de su libertad de expresión, y así se permitió escribir Galerías Preciadas (OI, 192), sireno (OI, 230), pulpa (OI, 286), Galaxio (OI, 316), cipresa (OI, 329), poeto (G, 121), Quijote y Sancha (HG 220) etc.

\section{Un apunte sobre antimilitarismo y feminismo}

Poco se ha investigado en el Estado español sobre este asunto. Hace casi un siglo tuvo lugar el I Congreso Internacional Mujeres por la Paz en la Haya, que transcurrió entre el 28 de abril y el 1 de mayo de 1915, y que apenas tuvo trascendencia en nuestro país. Faltaban dos años para que naciera Gloria Fuertes, cuando la I Guerra Mundial despedazaba Europa.

Ciento cincuenta mil soldados franceses murieron en un solo día cualquiera.

Era el año 1917, yo estaba aún en el vientre de mi madre.

("De guerra en guerra y matar les toca". MVP, 168-169)

Bajo la presidencia de Jane Addams, que recibiría el Premio Nobel de la Paz en 1931, alrededor de un millar de mujeres en representación de unas ciento cincuenta organizaciones de una docena de países, beligerantes y neutrales, se reunieron para elaborar una estrategia de paz y hacer un llamamiento a la mediación inmediata de los países neutrales dicho año de 1915. En el conjunto de las resoluciones destacaban: la creación de una conferencia de naciones neutrales y la petición de que se oyera la voz de las mujeres en los acuerdos de paz, a través de una conferencia de mujeres organizada en el mismo lugar donde se firmara (Hyman Alonso, 2010). Todos estos referentes se perdieron, y el movimiento feminista antimilitarista ha tenido que redescubrirlos no hace tanto. Como también hubo que enterarse de la existencia de Bertha von Suttner (1843-1914), cuyo Abajo las armas (1889) se tradujo al castellano en 1906, un año después de la concesión del premio Nobel de la Paz (la categoría más 
feminizada de estos premios) en su primera edición. Hasta Tres guineas (1938) de Virginia Woolf sigue siendo un texto apenas conocido (un estado de la cuestión: Magallón, 2006: 177-183 y 214-217).

En castellano, al menos, pocas monografías se han dedicado a recoger los esfuerzos de las mujeres en su lucha contra las guerras y contra la violencia, contra lo que difusamente pudiéramos denominar militarismo. Alguna traducción (VVAA, 2001), un interesante panorama de aportaciones a la paz de mujeres como Hannah Arendt, Christa Wolf, Marguerite Yourcenar, María Zambrano, y con especial atención a la helenista francesa Nicole Loraux (Ríus Gatell, 2006), y el que conforma el volumen más omnicomprensivo, con el sensible y necesario enfoque de Carmen Magallón (2006). Sobre mujeres españolas de los siglos XIX y XX, apenas un trabajo mío (Lorenzo, 2007), y habría que acudir a la bibliografía específicamente antimilitarista, no muy dada a derroteros académicos, para observar un interés en historiar y dar a conocer la labor de las mujeres a la hora de impugnar guerras y órdenes simbólicos de violencia en la España del siglo XX.

No pretendo hacer un estado de la cuestión exhaustivo de este tema, que sería un trabajo distinto, pero sí preparar el tema para señalar la importancia que la obra de Gloria Fuertes tiene en lo relativo a este punto de vista. Finalizo este epígrafe con unas palabras de Carmen Magallón, que glosan otras a su vez de Elena Grau, escritas en el Catálogo de la exposición Deposeu les armes! Tres creadores contra les guerres, celebrada en el Centre de Cultura de Dones Francesca Bonnemaison de Barcelona, centrada en Bertha von Suttner, Käthe Kollwitz y Marga Ximénez (2005):

\footnotetext{
“[...] la extrañeza o la ajenidad de las mujeres con respecto de la guerra no está en el plano de los hechos, sino en el de los significados, que sabe que optar por la ajenidad «significa ver que el patriarcado no lo ocupa todo», es ampliar el mundo para todas/os, «dar existencia a otro régimen de significado para otra política». Sin olvidar lo más importante. Y es que «la extrañeza tiene que ver con el amor. [Y...] el amor, que es siempre una apertura a recibir y a dar, crea relaciones ajenas a la política de la guerra»" (Magallón, 2006: 281-282).
}

Esta ajenidad adquiere en Gloria Fuertes tintes singulares gracias a su capacidad comunicativa y a la traducción lírica de unos sentimientos que responden a posicionamientos biográficos pero los trascienden, una ajenidad que, incluso tratando de estos temas, se traduce a veces en un fogonazo humorístico, que retuerce el dolor y cambia sorpresivamente la perspectiva de la situación. El humor como refugio de la vida, aun en las situaciones más desesperadas, como se cuenta en "Mejora la niña que nació con un bala": 
A su madre la dieron cuatro tiros en la tripa cuando estaba en avanzado período de gestación.

La niña-sin nacer-salvó a la madre, haciéndose cargo de la situación.

Después, unos médicos y unas oraciones salvaron a la niña gravemente afectada.

En vez de morirse -que era lo suyo¡cagó la bala!

(OI, 353)

\section{Estar en la gloria: la zona donde la paz se asoma}

La denuncia de la guerra llegó a ser una constante en la poesía de Gloria Fuertes, como se desprende también de otros testimonios, como sus entrevistas, apareciendo el tema con mayor asiduidad según van pasando los años, y llegando a ser casi un continuиm en sus últimos libros. El citado recuerdo de la Guerra Civil española, que ella padeció en su localidad natal, la castigadísima ciudad de Madrid, su ciudad, las noticias de prensa, el sufrimiento de la gente inocente... puso la sensibilidad de Gloria del lado de la razón y en contra de los responsables últimos de los conflictos bélicos. Uno de los poemas más sentidos de $M V P$ dice así:

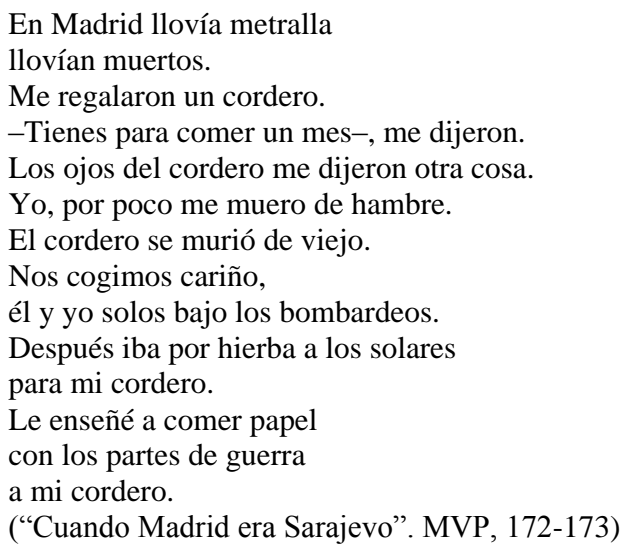


Estoy de acuerdo con Vila Belda (2008: 198) cuando afirma que "Fuertes transforma hábilmente unos recuerdos personales en colectivos y los convierte así en memoria cultural". Por ello considero radical el pacifismo de Gloria; porque parte de un diagnóstico global de la situación, y no de una repugnancia o escrúpulo individual para con las armas. Desde este punto de vista, el de la poeta puede considerarse antimilitarista, por identidad de planteamientos y metodologías a la hora de pensar el mundo, postura que con el tiempo va haciéndose más explícita, como se aprecia en el poema "Manos a la obra":

\footnotetext{
Basta con una mano para matar.

Necesitamos dos para acariciar,

dos para aplaudir,

todas las manos del mundo

para la paz.
}

(HG, 225)

Contra quienes promueven las guerras se muestra inmisericorde, sin un resquicio de esa empatía que derrochaba aquí y allá para con otras personas. No hay negociación posible y la voz se vuelve bronca, sin matices. Así entendía Gloria el "Nuevo pacifismo":

Disparen al disparador.

Destruyan al destruidor.

En cambio,

amen al amador

sigan al amador

persigan al disparador.

Disparen al disparador de la mente

para liberar al inocente.

Curen al odiador,

-si no acepta tu ternura-...

dispara tu corazón.

Mandato de la Naturaleza,

que la crueldad no siga

destruyendo la belleza.

(HG, 63)

Muchas de sus glorierías, fechadas en la década de los noventa, ya en el tramo final de su vida y cuando las mieles del éxito podrían haberla inducido a eliminar planteamientos explícitos problemáticos, lo expresan con precisión y con registros variadísimos. Glorierías fue el primero de sus libros póstumos, labor de edición y 
descubrimiento que continúa de la mano de la editorial Torremozas. Éstas son algunas, de las tantas vinculadas a este tema:

Que no duerman los cabrones

Que quieren usar la bomba de neutrones.

$(\mathrm{G}, 46)$

Sr. Enemigo:

-Déjeme ser su amigo.

(G, 133)

¿Por qué las guerras?

Si ya se muere uno sin que nadie le mate

$(\mathrm{G}, 150)$

Y un largo etcétera. Nos quedamos, no obstante, con dos versos inequívocos, que abren estas páginas, titulados "Medito" (G, 48), a cuya cita inicial remito. Solamente esas diez palabras, escritas en la vejez, bastarían para justificar, sin más, el título de este artículo. Una breve contextualización de los años en que se escriben subraya la apuesta de Gloria. En los años noventa el movimiento antimilitarista del Estado español había dado un salto cualitativo y también mediático. La campaña de Insumisión al Servicio Militar, con la negativa de miles de jóvenes a sostener el militarismo mediante su negativa a cumplir con dicho impuesto de sangre o la Prestación Sustitutoria que se instituyó en su lugar (cuando el primero era obligatorio) para intentar fortalecerlo y acallar las voces críticas, llevó a centenares de estos jóvenes a prisión (Ibarra, 1992; Agirre, Ajangiz, Ibarra y Sáinz de Rozas, 1998; En legítima..., 2002), visibilizando crudamente un problema puesto ya de manifiesto por los primeros objetores de conciencia "políticos" en España a principios de los años setenta del siglo pasado (Muñiz, 1974; Historia..., 1991). Este movimiento de desobediencia civil constituyó quizá uno de los más organizados y valientes posicionamientos políticos del siglo XX español, no mediado por siglas ni partidos políticos. Desde luego, el más visible y arriesgado desde las opciones noviolentas y colectivas. No me consta que Gloria Fuertes firmase manifiestos a favor de la Insumisión o se solidarizase públicamente con los insumisos presos en las cárceles españolas en aquellos años duros en que llegó a haber simultáneamente más de trescientos jóvenes privados de libertad por negarse radicalmente a colaborar con el militarismo. Tampoco me consta que nadie se lo pidiera. La poeta, ya se ha dicho, fue mediática, pero sólo en la faceta infantil. Más allá de ella, la discreción presidió su vida. 
Sin una alusión explícita, el sentimiento de Gloria Fuertes se solidarizó, una vez más, con quienes se opusieron a la garra de la guerra, apuntalándose ese interés en los últimos años de su vida, aunque un análisis de su obra descubra este sentimiento como un continuum en toda ella. Bajo este título precisamente, Garra de la guerra, se agruparon distintos poemas previos en un libro póstumo que ofrece una pequeña gavilla de poemas dedicados a este tema, seleccionados por Herrín Hidalgo (2002. Valencia, Media Vaca) con artísticas ilustraciones del artista anglo-libanés Sean Mackaoui. En el último libro publicado en vida de Gloria, Mujer de verso en pecho, hay una sección monográfica titulada "Haced sólo una zona, a ver si de una vez la paz se asoma (Poemas a la paz)", con 31 poemas relativos a este asunto (pp. 159-176), constituyendo la mayor densidad de los mismos escritos en un único volumen.

Desde luego, ya había dejado antes alta y clara la denuncia del armamentismo, en plena Guerra Fría, y eso que todavía faltaban seis años, cuando se publicó el libro al que pertenece el poema siguiente, para que se produjese el ingreso de España en la OTAN:

\footnotetext{
No se pueden seguir comprando más armas mientras el hambre aterra la tierra.

No se pueden seguir comprando armas para que el hombre aterre la tierra.

Una madre grita en la pradera:

-La peor paz es mejor que la mejor guerra.

("No se pueden seguir comprando armas". HG, 207)
}

Acabada la Guerra Fría, con nuestro país formando ya parte del cortejo de los vencedores, la denuncia es exactamente la misma, lamentándose de la impotencia que mostramos "millones de personas", la misma que los dioses. Unas y otros, como la poeta, parece que no tenemos más opción que contemplar la situación, como lo hicimos en su momento a través de la pantalla y los medios de comunicación, y lo seguimos haciendo, con cada periódico lance bélico, familiarizándonos con los mortíferos nombres de los ingenios de muerte.

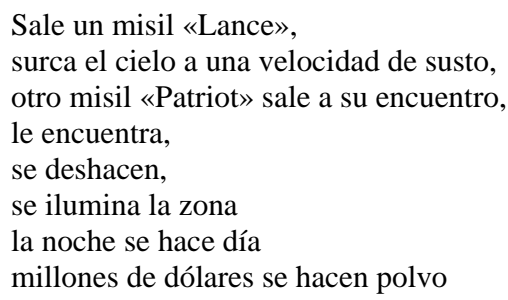


cientos de niños se hacen ceniza.

No hay campo de batalla,

es en la ciudad donde el diablo dice ¡hola!

Las bombas traspasan los refugios

silenciando el llanto de los niños.

Millones de personas no hacemos nada

para evitar el tormento.

(Solo lamentos).

Dios, Alá y Mahoma

tampoco evitan que caiga

ensangrentada una paloma.

(“Guerra moderna”. ED, 14)

El principio de la no colaboración, estrategia básica en el antimilitarismo noviolento, se expresa sin ambages en "Personajes ilustres":

-Prefiero seguir en "paro"

-me dijo Dimas Sarmiento-

antes de entrar en plantilla

en Fábrica de Armamento.

Yendo un paso más allá, hace un llamamiento a la deserción, ultima ratio si no puede evitarse el conflicto armado. Significativamente, la primera persona del plural ("Deseamos") es la forma empleada para enunciar el desideratum:

Deseamos:

Que no vuelva a haber otra guerra, pero si la hubiera, ique todos los soldados se declaren en huelga!

(HG, 237)

¿A cuántas voces públicas se les ha escuchado llamando a la deserción?

Tratando de proclamas significativas, la negación entendida como algo bueno, como rasgo de identidad, vuelve a ser dicha en un micropoema a modo de recapitulación de toda una vida ("Vejez". ED, 75):

Nací diciendo ajo y sí.

La vida me enseñó a decir coño y no.

Todo este corpus lírico, mantenido a lo largo de toda una biografía poética, supone uno de los corpora poéticos antibélicos más importantes en pluma de 
escritoras/es españolas/es del siglo XX. Adicionalmente, por el idiosincrático estilo de la autora, ofrece un material óptimo para reflexionar, trabajarlo y asomarnos de una manera aparentemente muy sencilla y directa a la hondura de unas reflexiones y a la disección de ciertos sentimientos a través de un proceso mediado por la escritura de quien tiene un don. No son poemas resignados, de simple condolencia con las víctimas. Son textos rabiosos muchos de ellos, que toman partido, que señalan culpables.

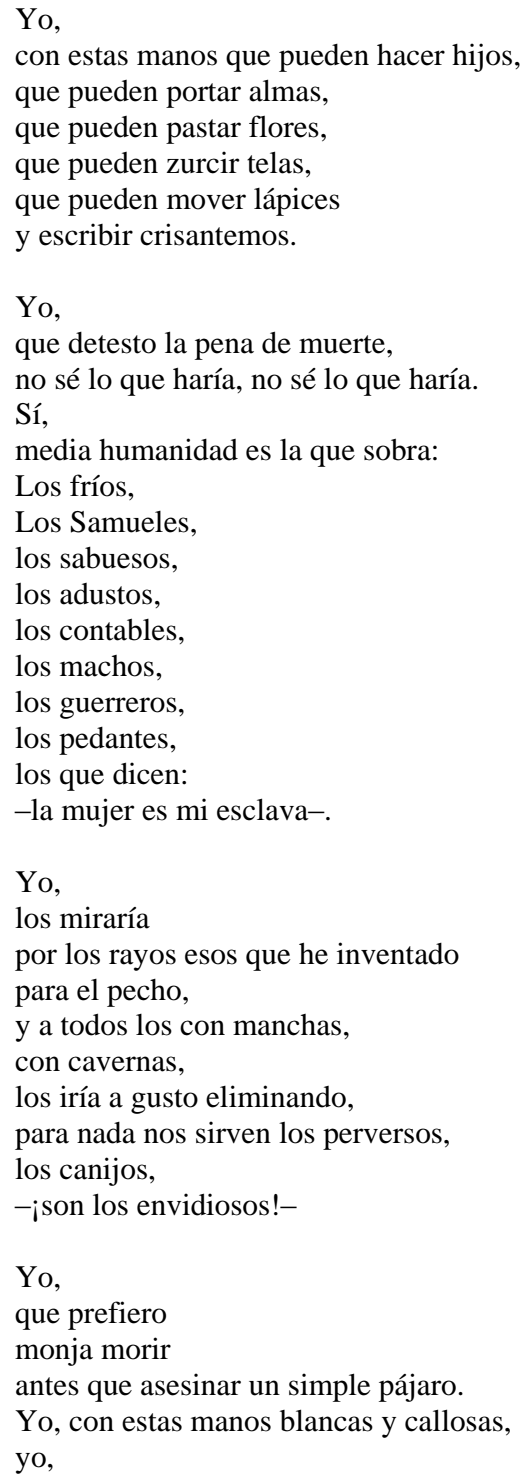


que detesto la pena de muerte, no sé lo que haría.

("Mal sueño". PS, 29-30)

Además de los poemas agrupados en los dos libros citados (Garra de la guerra y Mujer de verso en pecho), podrían aducirse otros títulos, más de un centenar, espigados de entre los muchos que componen la obra lírica de Gloria Fuertes, permitiendo afirmar que el objetivo de la autora, su más anhelado deseo, fue la abolición de las guerras y de la violencia. A ello se dedicó con su pluma, a construir una “zona de paz" desde su oficio de poeta, una paz en cuya justificación se entreveran razones de su pacifismo inquebrantable y cuestiones biográficas. Así, en "Por qué no me he casado" (HG, 303) explica cómo un novio que tuvo en 1936 hubo de escoger entre "el poder y la Gloria", eligiendo la política, y poco después, a otro

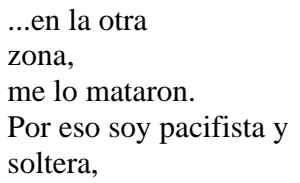

marcando claramente, entre otras cosas, las consecuencias de la violencia y su rechazo, venga de donde venga. Quizá estas circunstancias tenía en la cabeza cuando escribe "Cayó para nada", poema escrito sesenta años después de los acontecimientos, o quizá eran las imágenes de los telediarios, en que cada día la tragedia, aquí y allá se repite, como si nunca pudiéramos aprender. Como si siempre, hubieran de morir los mismos.

Corazón de cereza tenía aquel soldado. Tenía ojos brillantes tenía quince años. Iba el primero. Tres cerezas brotaron del bolsillo izquierdo de su chaquetón. Cayó para nada. (ED, 16) 


\section{Un apunte biográfico final, como epílogo}

En numerosos libros y artículos se sigue manteniendo la confusión sobre su fecha de nacimiento, barajándose tres fechas: 1917, 1918 y hasta 1920. Con estas breves líneas queremos contribuir a disipar cualquier tipo de duda de aquí en adelante sobre este particular, fácilmente demostrable. Como historiador que soy, es mi pequeña aportación desde mi oficio.

Gloria Fuertes García nació a las 3,30 h. del día 28 de julio de 1917 en la portería de la madrileña calle de la Espada (Lavapiés) número 9. Sus padres fueron José Fuertes Gimeno y Gloria García López, respectivamente naturales de Madrid y Covarrubias (Burgos). Sus abuelos paternos procedían de Cangas de Tineo (Asturias) y Madrid, y los maternos de la misa localidad que la madre. Gloria fue hija de familia muy numerosa.

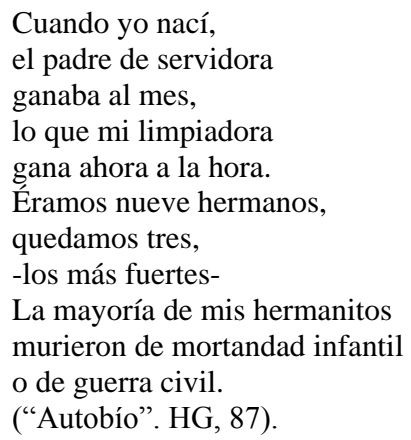

Es probable que, por lo que fuere, Gloria alentase las incógnitas sobre el año concreto del nacimiento. Si se ha mantenido una confusión con la fecha exacta de su nacimiento, su testamento (por el que dejó una cuantiosa suma económica a la Ciudad de los Muchachos de Leganés) contribuye aún más al malentendido, pues afirma que nació un mes antes de la fecha real, por una errata. Se compensa, no obstante, con la certera descripción de su oficio: "Doña Gloria Fuertes García, nacida en Madrid, el día 28 de Junio de 1917, hija de Jose y de Gloria, soltera, de profesión Poeta, vecina de Madrid [...]".

Se ha interpretado como un apunte surrealista el que expresa la propia Gloria en tercera persona en su famosa Nota biográfica (PS, 13-14; OI, 41-42), afirmando que nació a los dos días de edad (Vila Belda, 2008: 198): 
Gloria Fuertes nació en Madrid

a los dos días de edad,

pues fue muy laborioso el parto de mi madre

que si se descuida muere por vivirme (...)

Quizá refiera esa fecha a su "nacimiento civil", pues fue inscrita por su padre en el Registro Civil (Sección 1ª del Libro1447, f. 317. Madrid) efectivamente dos días después de nacer en el propio domicilio paterno, el 30 de julio de 1917. El religioso llegaría más tarde, siendo bautizada en la cercana parroquia del Buen Consejo (la antigua Catedral de San Isidro) el 9 de agosto (Archivo Parroquial de Ntra. Sra. del Buen Consejo. Libro de Bautismos $n^{\circ}$ 6, f. 347v, asiento $n^{\circ} 187$ ).

Gloria Fuertes, que le hablaba a Dios de "tú", que por desnudarle la censuraron en Televisión Española (publicó un poema en 1975 titulado "Resulta que Dios está desnudo", OI, 137), debe estar ahora cara a cara con Él. Y le tuteará. Por voluntad propia no estará en ningún Parnaso donde literatos serios de todos los tiempos prosiguen eruditas tertulias, sino en esos suburbios celestiales donde el común del pueblo está.

La gloria de Dios, ese Dios al que la poeta tantos versos dedicara, es aún más gloria, con minúscula y con mayúscula. Por ello, y sin ningún ánimo ofensivo, podemos cambiar la fórmula "Gloria in excelsis Deo", y decir Glorie in excelsis Deus. A Gloria, que tanto jugó con su nombre en sus poemas, esta combinación no se le ocurrió. Claro, que era mucho menos pedante. Qué bien se lo estarán pasando los ángeles. 


\section{BIBLIOGRAFÍA}

- Acereda, A. (1999): “Autobiografía y sentido en el mundo poético de Gloria Fuertes”. En Letras Femeninas, n 25 , pp. 155-172.

. (2000): “Crítica y poética en Gloria Fuertes. Intertextualidades culturales de una poética contestataria”. En Monteagudo. Revista de Literatura Española, Iberoamericana y Teoría de la Literatura, $\mathrm{n}^{\circ}$ 5, pp. 143-157.

. (2002): d En Romance Quaterly, no 49/3, pp. 228-240.

- Agirre, X.; Ajangiz, R., Ibarra, P. y Sáinz de Rozas, R. (1998): La insumisión. Un singular ciclo histórico de desobediencia civil. Madrid: Tecnos.

- Benson, D. (1994): “Tres calillas en Gloria Fuertes (poesía)”. En RILCE, n 6/2, pp. 211-43.

. (2000): "La voz inconfundible de Gloria Fuertes, 1918-1998: poesía temprana". En Hispania, no 83/2, pp. 210-221.

. (2003): El juego de palabras en la poesía de Gloria Fuertes. Madrid: Universidad Nacional de Educación a Distancia.

- Berzal de la Rosa, E. (2010): "Hitos clave en la historia de Ruedo Ibérico". En G. Santonja y E. Berzal de la Rosa (eds.): Los libros de Ruedo Ibérico o la libertad en el laberinto, Valladolid, Instituto Castellano y Leonés de la Lengua, pp. 43-62.

- Browne, P. (2000): “El amor por lo (par) odiado: la poesía de Gloria Fuertes y Ángel González”. En Hispanofilia, nº 129, pp. 139-141.

- Cappuccio, B. (1993): "Hambre y poesía: una breve bibliografía de Gloria Fuertes". En Anales de la literatura española contemporánea, $\mathrm{n}^{\circ}$ 18, 1-2, pp. 323-344.

- Debicki, A. P. (1986): "Gloria Fuertes: intertextualidad e inversión de expectativas". En Poesía del conocimiento: la generación española de 1956-1971. Madrid: Júcar.

- En legítima desobediencia. Tres décadas de Objeción, Insumisión y Antimilitarismo (2002). Madrid: MOC-Proyecto editorial Traficantes de Sueños.

- Fernández Rodríguez, L. J. (1998): "La lengua coloquial en la poesía de hoy: el ejemplo de Gloria Fuertes". En Cahiers du P.R.O.H.E.M.I.O., $\mathrm{n}^{\circ} 2$ (Actes du colloque international "Usages de la formule", 21-22 novembre 1997), pp. 141-155.

(1999): “Las expresiones fijas en la última poesía de Gloria Fuertes”. En Paremia, nº 8, pp. 171-178.

- Folkart, J. A. (2000/2001): “Turning Tricks: Opposionality and Readerly Seduction in the Poetry of Gloria Fuertes”. En Letras Peninsulares, 13/2, pp. 787-801.

- García Selma, M. D. (2004): "La búsqueda de una identidad literaria. Un siglo de poesía escrita por mujeres”. En Conferencias, pp. 117-125. 
- García-Page, M. (1990): “Juegos lingüísticos de Gloria Fuertes: Ekfrasis y poesía”. En Letras Femeninas, ${ }^{\circ}$ XXIX/2, pp. 85-97.

- Historia de la Objeción de Conciencia en el Estado español... Una alternativa de paz (1991): Córdoba: Comisión de Paz y Objeción de Conciencia del Consejo Local de la Juventud de Córdoba.

- Hyman Alonso, H. (2010): "Los inicios de la construcción del movimiento pacifistafeminista”. En M. ${ }^{a}$ E. Díez Jorge y M. Sánchez Romero (eds.): Género y paz. Barcelona: Icaria, pp. 83-110.

- Ibarra, P. (ed.) (1992): Objeción e insumisión. Claves ideológicas y sociales. Madrid: Fundamentos.

- Lorenzo Arribas, J. (2007): “Tensiones militarismo/antimilitarismo". En Escritoras y periodistas en Madrid (1876-1926). Madrid: Ayuntamiento de Madrid, pp. 124-174.

- Magallón, C. (2006): Mujeres en pie de paz. Pensamiento y prácticas. Madrid, Siglo XXI.

- Mandlove, N. (1987-1988): “Oral Texts: The Play of Orality and Literacy in the Poetry of Gloria Fuertes”. En Siglo XX, n 51-2, pp. 11-16.

. (1983): "Used Poetry: The Trans-parent Language of Gloria Fuertes and Angel González". En M. H. Persin et al.: Metaliterature and Recent Spanish Literature, Revista Canadiense de Estudios Hispánicos, nº 7.2, pp. 301-306.

- Morris, B. C. (1991): "Strategies of Self-Effacement in Three Poems of Gloria Fuertes”. En Mester, no 20, pp. 67-78.

Muñiz, G. (1974): Los objetores de conciencia ¿delincuentes o mártires?. Madrid: Speiro.

- Payeras Grau, Ma. (2003): El linaje de Eva. Tres escritoras españolas de posguerra. Madrid: Sial.

Pellarolo, S. (1992): "La poesía de Gloria Fuertes o el ingenioso distanciamiento de sí misma”. En Literatura femenina contemporánea de España. Los Angeles, California State University Northridge, pp. 69-78.

- Persin, M. (1988): "Humor as Semiosis in the Poetry of Gloria Fuertes". En Revista hispánica moderna, $\mathrm{n}^{\circ}$ 41/2, pp. 143-158.

- Ramón, E. (2006): “Gloria Fuertes: la poesía como alternativa femenina ante lo establecido". En Espéculo. Revista de estudios literarios, XI, n 32 [en línea] Disponible en: http://www.ucm.es/info/especulo/numero32/gfuertes.html [13/02/2011].

- Reina Ruiz, Ma . (2003): "La otra mirada la posmodernidad y la poesía española de posguerra”. En Siglo XXI, no 12, pp. 69-85.

. (2003): "La otra mirada de Gloria Fuertes. Ékfrasis y poesía”. En Letras Femeninas, no $29 / 2$, pp. 85-96. 
- Ríus Gatell, R. (2006): Sobre la guerra y la violencia en el discurso femenino (19141989). Barcelona: Universitat de Barcelona.

- Sherno, S. (1990): “Gloria Fuertes: Room of Her Own”. En Letras Femeninas, XVI, 1-2, pp. 85-99.

. (1989-90): “The Poetry of Gloria Fuertes: Textuality and Sexuality". En Siglo $\overline{X X / 20} 0^{\text {th }}$ Century, $\mathrm{n}^{\mathrm{o}} 7,1-2$, pp. 19-23.

- Ten Hacken, H. (2007): Self-definition through poetry in the work of Gloria Fuertes and Pilar Paz Pasamar in the period 1950-1970. Ph.D. University of St Andrews.

- Vila Belda, R. (2008): "Pan y versos: hambre y subversión en la poesía de Gloria Fuertes". En Bulletin of Spanish Studies. Hispanic Studies and Research on Spain, Portugal and Latin America, vol. 85/2, pp. 193-215.

- VVAA. (2001): Guerras que yo he visto. Saberes de mujeres en la guerra. Madrid: horas y HORAS.

\section{Obras de Gloria Fuertes citada en el texto:}

ED: $\quad$ Es difícil ser feliz una tarde, Madrid, Ediciones Torremozas, 2005.

G: $\quad$ Glorierías (para que os enteréis), Madrid, Ediciones Torremozas, 2001.

HG: Historia de Gloria: (amor, humor y desamor), Madrid, Cátedra, 1980.

MVP: $\quad$ Mujer de verso en pecho, Madrid, Cátedra, 1995.

OI: $\quad$ Obras incompletas, Madrid, Cátedra, 1975.

PS: $\quad$ Poemas del suburbio, Madrid, Ediciones Torremozas, 2004 [1 $\left.{ }^{\mathrm{a}} \mathrm{ed} .1954\right]$. 